\section{THU0058 ENHANCEMENT OF CARTILAGE REGENERATION EFFICIENCY WITH HUMAN ADIPOSE STEM CELL THREE-DIMENSIONAL SPHEROID}

J. Y. Ko ${ }^{1}$, E. Lee ${ }^{1}$, J. Kim ${ }^{1}$, G. I. Im ${ }^{1}{ }^{1}$ Research Institute for Integrative Regenerative Biomedical Engineering, Dongguk University, Goyang, Korea, Rep. of (South Korea)

Background: 3D (three-dimensional) cell culture technology has been researched steadily because of its high potential of biocompatibility compared to single cells since 1990s, and is being developed to 3D spheroids recently. Spheroids are considered to reflect the natural organization of cells better than $2 \mathrm{D}$ cell cultures, and stem cells spheroids have been studied extensively in therapeutic transplantation. Stem cells were considered as a method of replacing autologous chondrocyte in regenerative treatment of articular cartilage. Compared to conventional single cells, 3D cell culture is artificially created an environment similar to a living body in vitro so that all cells collectively, a cell culture model that allows growth or interaction with the environment. Therefore, the findings of this study indicate that enhancement of treatment efficiency of stem cells caused by potential of survival and proliferation of hASC spheroid in Osteoarthritis. In conclusion, spheroid positive subpopulation of hASCs has high cell proliferation and survival but not apoptosis and cell death potential, which may contribute to successful cartilage regeneration and the development of stem cell therapies in the future.

Objectives: Studied for 3D spheroids to investigate the mechanism of enhancement of survival and proliferationof hASC (human adipose stem cells) spheroid, which may contribute to successful improvement of therapeutic efficacy of stem cells.

Methods: Cell isolation and culture / 3D cell culture dish preparation / hASCs culture on 3D cell culture dish / Real-time PCR analysis / Western blotting / Alcian blue staining / ACLT + MM (Anterior cruciate ligament transection with Medial meniscectomy) model / In vivo fluorescence for cell tracking / In vivo effects of spheroids in OA joint / Histological analysis / Enzyme-linked immunosorbent assay (ELISA) results for inflamma -tory cytokines in rat synovial fluid / Statistical Analysis

Results: In order to see how the spheroid showed more residual than single, and how effective it was in actual cartilage regeneration, the result of paraffin tissues were confirmed by safranin $\mathrm{O}$ staining for each condition. The tendency of cartilage regeneration efficiency was good for spheroid. Although the differences between the single and spheroid groups were small, they reaffirmed that they could somewhat protect cartilage and help regeneration treatment. However, immunohistochemistry of $\mathrm{HN}$ (Human nucleic antigen) staining showed that cells of single and spheroid were not observed in the wound but disappeared by the paracrine effect.

Conclusion: Spheroids do not exhibit differentiation characteristics, but they could be seen as a result of expression of related genes such as Bax, Bcl-XL and Alcian blue staining. Spheroids tend to have low potential of cell death rather than proliferation and reduction in the proliferation. So, we conclude the fact that instead of hASCs going directly to the surgical site to regenerate cartilage, they can help catrilage regeneration.

\section{(A) In vitro}
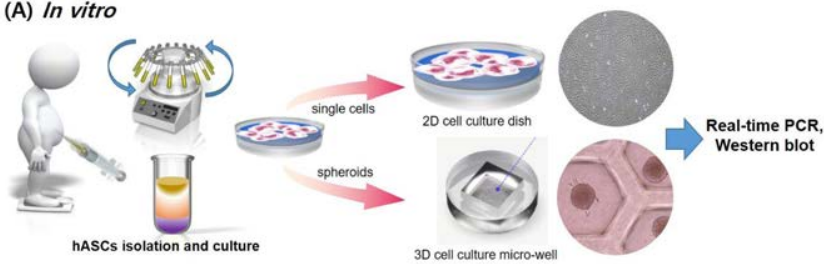

(B) In vivo

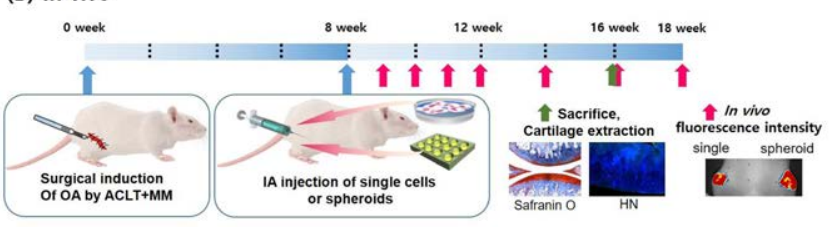

Figure 1. General scheme of in vitro and in vivo experiments using spheroid. (A) in vitro experimental procedures to identify single
and spheroid. (B) in vivo experimental procedures in surgically-induced $O A$ model to identify the cartilage regeneration efficiency
of spheroid.

Acknowledgments: This research was supported by the National Research Foundation of Korea (NRF-2019R1H1A2039685 and 2019R1I1A1A01043778). Disclosure of Interests: None declared DOI: 10.1136/annrheumdis-2020-eular.4022

\section{THU0059 \\ INCREASING SURFACE LUBRICATION WITH POLY(2- METHYL-2-OXAZOLINE) HALTS DEGENERATIVE CHANGES IN THE CARTILAGE IN A COLLAGENASE INDUCED OSTEOARTHRITIS (CIOA) RAT MODEL}

S. Kauppinen $^{1}$, D. Fercher ${ }^{2}$, G. Barreto ${ }^{3}$, G. Morgese ${ }^{2}$, E. Benetti ${ }^{2}$, S. Saarakkala ${ }^{1}$, H. Nieminen ${ }^{4}$, M. Zenobi-Wong ${ }^{2}$, M. A. Finnilä ${ }^{1}{ }^{1}$ University of Oulu, Oulu, Finland; ${ }^{2}$ ETH Zürich, Zürich, Switzerland; ${ }^{3}$ University of Helsinki, Helsinki, Finland; ${ }^{4}$ Aalto University, Espoo, Finland

Background: Degenerative lesions of articular cartilage (AC) surface are related to disruption of the well-organized collagen network and allow proteoglycans to escape from the tissue. Ultimately, this leads to the development of osteoarthritis (OA). Targeted therapy for early AC lesions could provide an effective way to halt the OA development process.

Objectives: This study aims to evaluate the effectiveness of an engineered surface lubricant; poly(2-methyl-2-oxazoline) (PMOXA) ${ }^{1}$ to prevent the destruction of the AC surface. Our recently developed contrast-enhanced $\mu C T$ (CE $\mu C T)$ method was used to quantify AC surface erosion ${ }^{2}$

Methods: OA was induced in $12-18$ week-old male Wistar rats $(\mathrm{N}=17)$ with an injection of $250 \mathrm{U}$ Collagenase within $25 \mu \mathrm{L}$ solution into the left hind limb. Both hind legs were treated with a second injection three days after the collagenase injection $(\mathrm{Cl})$. Three groups were formed by using either PMOXA $(\mathrm{N}=5)$, hyaluronic acid $(\mathrm{HA} ; \mathrm{N}=6)$, or saline $(\mathrm{N}=6)$ during the second injection. The animals were sacrificed after 45 days, and harvested knees were fixed in phosphate-buffered formalin for a week. Knees were stored in $70 \%$ ethanol, and tibia and femur were carefully dissected free of other tissue, stained with $1 \%$ phosphotungstic acid $^{3}$, and scanned with a desktop $\mu C T$ with $2.8 \mu \mathrm{m}$ pixel size. The medial and lateral $A C$ surfaces were manually segmented from 3D projections using an in-house developed program (Matlab sofware). These surfaces were analyzed by iteratively fitting a reference surface (RS) to a median-filtered smoothed surface representing a perfectly smooth surface, capturing the realistic shape AC. An offset of 5 pixels $(14 \mu \mathrm{m})$ was added between the RS and the original surface (OS) Two quantitative parameters were calculated from the data: Average of Maximum Void Depth (MVD) (depth of lesion) and Degeneration-\% (area exceeding $20 \mu \mathrm{m}$ MVD / whole area) ${ }^{\star} 100$ ). Estimates of mean differences from all groups against the $\mathrm{Cl}+$ Saline -group were determined using a linear mixed model.

Results: Boxplots from tested groups are shown in Fig. 1A and MVD results are visualized in Fig. 1B. Collagenase caused structural defects only on the medial and lateral tibial AC surfaces, which was seen as increased MVD and Degeneration-\%. $\mathrm{Cl}$ changes were not seen in PMOXA or HA treated groups. Furthermore, MVD and Degeneration\% were lower in $\mathrm{CI}$ knees that were treated with PMOXA. Conclusion: Our $\mathrm{CE} \mu \mathrm{CT}$ analysis method was able to detect subtle changes of the AC surface in the medial and lateral tibial cartilage, caused by the $\mathrm{Cl}$ In contrast, the $\mathrm{Cl}$ did not cause detectable changes in the $\mathrm{AC}$ of the femur, which indicates that in the CIOA model, the tibia is more susceptible to structural degradation. Our results show that early intervention with HA or PMOXA can halt the degenerative $\mathrm{AC}$ changes caused by $\mathrm{Cl}$. However, HA did not suppress the effects of $\mathrm{Cl}$ in the medial tibia, which indicates that PMOXA could be more effective to prevent the development of OA.

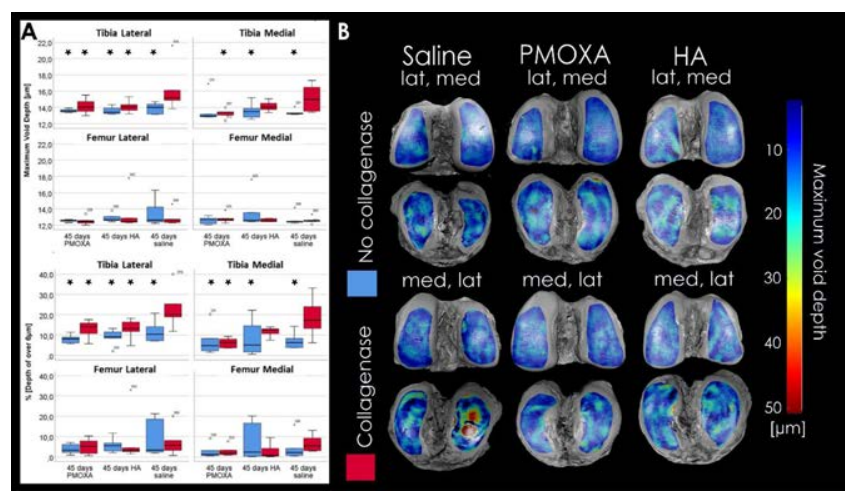

Figure 1. A) Boxplots of Maximum Void Depth (MVD) and Degeneration-\%. Lateral and media side are analyzed separately for both tibias and femurs. Stars indicate if a group was statistically different from control group $(\mathrm{Cl}+\mathrm{Saline}) . \mathrm{Cl}=\mathrm{red}$, no $\mathrm{Cl}=$ blue. $\mathrm{B})$ Representative visualizations for maximum void depth overlayed on top of the 3D AC surface.

\section{References:}

[1] Morgese G, et al. Hairy and slippery polyoxazoline-based copolymers on model and cartilage surfaces. Biomacromolecules 201819 (2), 680-690 
[2] Ylitalo T, et al. Quantifying Complex Micro-Topography of Degenerated Articular Cartilage Surface by Contrast-Enhanced Micro-Computed Tomography and Parametric Analyses. J Orthop Res. 2019 Apr;37(4):855-866.

[3] Nieminen $\mathrm{HJ}$, et al. Determining collagen distribution in articular cartilage using contrast-enhanced micro-computed tomography. Osteoarthritis Cartilage. 2015;23(9):1613-1621

Disclosure of Interests: None declared

DOI: 10.1136/annrheumdis-2020-eular.1673

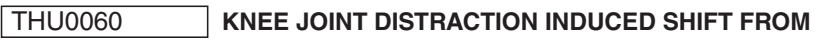 CATABOLIC TO ANABOLIC STATE OCCURS AFTER DISTRACTION PERIOD}

M. Teunissen ${ }^{1}$, J. Popov-Celeketic ${ }^{2}$, K. Coeleveld ${ }^{2}$, B. Meij ${ }^{1}$, F. Lafeber ${ }^{2}$, M. Tryfonidou ${ }^{1}$, S. Mastbergen ${ }^{2} .{ }^{1}$ Utrecht University, Utrecht, Netherlands; ${ }^{2}$ UMC Utrecht, Utrecht, Netherlands

Background: Knee joint distraction (KJD) is a validated joint-preserving treatment strategy for severe osteoarthritis $(\mathrm{OA})$ that provides long-term clinical and structural improvement. Human trials and animal models indicate clear cartilage regeneration from 6 months and onwards post-KJD [1]. Recent work showed that during distraction, the balance between catabolic and anabolic indicators is directed towards catabolism, as indicated by collagen type 2 markers, proteoglycan (PG) turnover and a catabolic transcription profile.

Objectives: To investigate the cartilage changes directly and 10 weeks after joint distraction in order to elucidate the shift from a catabolic to an anabolic cartilage state.

Methods: Knee OA was induced bilaterally in 8 dogs according to the groove model. After 10 weeks of OA induction, all 8 animals were treated with knee joint distraction, employing the left knee as an OA control. After 8 weeks of distraction, 4 dogs were euthanized $\left(\mathrm{KJD}_{\text {dirct }}\right)$ and after 10 weeks of follow-up the 4 remaining dogs $\left(\mathrm{KJD}_{+10}\right)$. Macroscopic and microscopic cartilage degeneration was assessed using the OARSI canine scoring system. RT-qPCR was used to determine relative expression of aggrecan (ACAN), collagen type II (COL2a1), cartilage oligomeric matrix protein $(C O M P)$ and matrix metalloproteinase-3 (MMP3) in the cartilage. PG content was determined by the Alcian Blue assay and the synthesis of PGs was determined using ${ }^{35} \mathrm{SO}_{4}{ }^{2-}$ as a tracer, as published before.

Results: Macroscopic cartilage damage of the tibial plateau in the KJD group was higher as compared to the OA control (OARSI score: $1.7 \pm 0.2$ vs $0.6 \pm 0.3 ; p<0.001$ ). For KJD K $_{+10}$ this difference persisted (OARSI score: $1.4 \pm 0.6$ vs $0.6 \pm 0.3 ; p=0.05)$. Microscopically, an increase in the total OARSI score was seen after 10 weeks post-KJD. This was mainly due to an increase of chondrocyte clusters at 10 weeks of follow-up, resulting in an increased sub score chondrocyte pathology. Remarkedly the sub score intensity of proteoglycan staining decreased directly after KJD (indicating a loss of PGs) but increased after 10 weeks of follow-up suggesting a mixed response depending on the item scored.

Cartilage gene expression analysis showed downregulation of COL2a1 (-1.3 \pm $0.3), \operatorname{ACAN}(-4.4 \pm 1.0, p<0.01)$ and COMP $(-1.7 \pm 0.5)$ in the group compared to $\mathrm{OA}$ control suggesting enhanced catabolic activity during KJD. In contrast, after 10 weeks of follow-up the expression of COL2a1 and COMP were increased as compared to the OA control $(2.6 \pm 1.1$ and $2.5 \pm 1.2$ respectively) as well as compared to the $\mathrm{KJD}_{\text {direc }}$ situation $(3.3 \pm 1.4$ and $4.2 \pm 2.0)$. Expression of MMP3 was upregulated directly after KJD $(4.4 \pm 0.8)$ and downregulated after 10 weeks of follow up $(-3.3 \pm 0.8)$.

Biochemical analysis of the tibia cartilage of the $\mathrm{KJD}_{\text {direct }}$ group revealed a lower PG content compared to the OA joint $(20.1 \pm 10.3 \mathrm{mg} / \mathrm{g}$ vs $23.7 \pm 11.7 \mathrm{mg} / \mathrm{g})$. At 10 weeks post-KJD this difference in PG content was gone $(24.8 \pm 6.8 \mathrm{mg} / \mathrm{g}$ vs $25.4 \pm 7.8 \mathrm{mg} / \mathrm{g}$ ). The PG synthesis rate directly after KJD appeared significantly lower vs. OA $(1.4 \pm 0.6 \mathrm{nmol} / \mathrm{h} . \mathrm{g}$ vs $5.9 \pm 4.4 \mathrm{nmol} / \mathrm{h} . \mathrm{g} ; p<0.001)) .10$ weeks post$\mathrm{KJD}$ this difference was not detected $(3.7 \pm 1.2 \mathrm{nmol} / \mathrm{h} . \mathrm{g}$ vs $2.9 \pm 0.8 \mathrm{nmol} / \mathrm{h} . \mathrm{g})$, and the synthesis rate in the distracted knee was increased compared to directly after distraction $(p<0.01)$ indicating a shift upon follow-up.

Conclusion: Further in-depth investigation of the material is ongoing and also includes the other joint tissues such as the bone and the synovial tissue. Irrespective, these first results on cartilage changes suggest that the shift from a catabolic to an anabolic state occurs within the weeks after joint distraction. As such, the post-distraction period seems to be essential in identifying key-players that support intrinsic cartilage repair.

References:

[1] Mastbergen SC, Nat Rev Rheumatol. 2013 May;9(5):277-90.

Acknowledgments: TTW Technology Foundation: Perspectief P15-23, Dutch Arthritis Society: Long term Research Program LLP9

Disclosure of Interests: Michelle Teunissen: None declared, Jelena Popov-Celeketic: None declared, Katja Coeleveld: None declared, Bjorn Meij:
None declared, Floris Lafeber Shareholder of: Co-founder and shareholder of ArthroSave BV, Marianna Tryfonidou: None declared, Simon Mastbergen: None declared

DOI: 10.1136/annrheumdis-2020-eular.2847

\begin{tabular}{|l}
\hline THU0061 \\
EVALUATION OF SAFETY AND EVOLUTION \\
OF OSTEOARTHRITIC JOINTS AFTER THE \\
ADMINISTRATION OF HETEROLOGOUS \\
MESENCHYMAL STROMAL CELLS IN AN ANIMAL \\
MODEL
\end{tabular}

${ }_{\text {P. C. Sánchez-Pedreira }}{ }^{1}$, Á. Vela-Anero ${ }^{2,3}$, N. Otero Queijas ${ }^{2,3}$, M. Lorenzo Toja $^{3}$, A. Somaza Serantes ${ }^{3}$, T. Hermida Gómez ${ }^{1,2,4}$, F. J. Blanco ${ }^{1} .{ }^{1}$ Unidad de Medicina Regenerativa, Grupo de Investigación en Reumatología (GIR), Agrupación Estratégica CICA-INIBIC, A Coruña, Spain; ${ }^{2}$ Integral Vetter Medicina Veterinaria Integrativa, A Coruña, Spain; ${ }^{3}$ Hospital Veterinario Cuatro de Octubre, A Coruña, Spain; ${ }^{4}$ CIBER-BBN, Madrid, Spain

Background: One of the main osteoarthritis $(O A)$ consequences is the cartilage loss. Nowadays there is not cure for the OA, so there is an intense research focused on finding a therapy to solve this problem. In this paradigm heterologous mesenchymal stromal cells $(\mathrm{MSCH})$ rise as a solution. Different studies used them as a cellular therapy in order to regenerate damaged cartilage. Furthermore, MSCH have shown anti-inflammatory effects.

Objectives:

1) Study the safety of a single intraarticular injection of $\mathrm{MSCH}$ derived from healthy canine fat tissue (adMSCH) in OA joints of dogs

2) Observe the evolution of functionality and range of articular mobility of these treated joints 6 months after the injection.

Methods: adMSCH obtained $(n=10)$ were phenotypically characterized by flow cytometry, including the Major Histocompatibility Complex type II (MHC-II). Those with the best morphology and growth $(n=5)$ were used for the injection. The infiltrated dogs $(n=7)$ met our inclusion/exclusion criteria. The adMSCH were injected in 11 joints by 1 million of cells/kilogram of weight.

Before the infiltration we evaluated the joints (basal visit, BV), the vital signs and the animal pain by the owner (Visual Analogical Scale, VAS). The same data were collected one week after the infiltration (V1) and also studied the injected zone. Six months after treatment (V2), joint functionality and range of articular mobility were evaluated, also data of behavioural changes and pain observed by the owners.

Table 1. Functionality and range of articular mobility comparison between BV and V2. Visits column show the number of joints in that state

\begin{tabular}{|c|c|c|c|c|c|c|}
\hline & \multirow[t]{2}{*}{ Variable } & \multirow[t]{2}{*}{ Answers } & \multicolumn{2}{|c|}{ Visits } & \multirow{2}{*}{$\begin{array}{l}\mathrm{t} \text {-student } \\
\text { (p-value) }\end{array}$} & \multirow[t]{2}{*}{$\mathrm{n}$} \\
\hline & & & BV & V2 & & \\
\hline \multirow{16}{*}{ FUNCTIONALITY } & \multirow{4}{*}{ Load changes } & Normal & 3 & 7 & \multirow[t]{4}{*}{0.095} & \multirow[t]{4}{*}{11} \\
\hline & & Change load & 8 & 4 & & \\
\hline & & Support fingers & 0 & 0 & & \\
\hline & & No support & 0 & 0 & & \\
\hline & \multirow{4}{*}{$\begin{array}{l}\text { Load changes when } \\
\text { getting up }\end{array}$} & Correctly & 1 & 6 & \multirow[t]{4}{*}{$0.024^{*}$} & \multirow[t]{4}{*}{11} \\
\hline & & $\begin{array}{l}\text { Position } \\
\text { modification }\end{array}$ & 10 & 5 & & \\
\hline & & $\begin{array}{l}\text { Difficulty to } \\
\text { get up }\end{array}$ & 0 & 0 & & \\
\hline & & No get up & 0 & 0 & & \\
\hline & \multirow[t]{4}{*}{ Lameness in cold } & No lameness & 1 & 2 & \multirow[t]{4}{*}{0.062} & \multirow[t]{4}{*}{11} \\
\hline & & Mild lameness & 6 & 9 & & \\
\hline & & $\begin{array}{l}\text { Intense } \\
\text { lameness }\end{array}$ & 4 & 0 & & \\
\hline & & No support & 0 & 0 & & \\
\hline & \multirow{4}{*}{$\begin{array}{l}\text { Lameness when } \\
\text { warmed }\end{array}$} & No lameness & 1 & 3 & \multirow[t]{4}{*}{0.106} & \multirow[t]{4}{*}{11} \\
\hline & & Mild lameness & 8 & 8 & & \\
\hline & & $\begin{array}{l}\text { Intense } \\
\text { lameness }\end{array}$ & 2 & 0 & & \\
\hline & & No support & 0 & 0 & & \\
\hline \multirow{11}{*}{$\begin{array}{l}\text { RANGE OF } \\
\text { ARTICULAR } \\
\text { MOBILITY }\end{array}$} & \multirow{4}{*}{$\begin{array}{l}\text { Articular passive } \\
\text { manual mobility }\end{array}$} & Without pain & 0 & 0 & \multirow[t]{4}{*}{0.400} & \multirow[t]{4}{*}{11} \\
\hline & & Mild pain & 3 & 5 & & \\
\hline & & Raised pain & 8 & 6 & & \\
\hline & & Disabling pain & 0 & 0 & & \\
\hline & \multirow[t]{3}{*}{ Flexion limitation } & Total flexion & 9 & 8 & \multirow[t]{3}{*}{0.750} & \multirow[t]{3}{*}{11} \\
\hline & & Mild limitation & 1 & 2 & & \\
\hline & & $\begin{array}{l}\text { Severe } \\
\text { limitation }\end{array}$ & 1 & 1 & & \\
\hline & \multirow[t]{4}{*}{ Extension limitation } & Total extension & 0 & 3 & \multirow[t]{4}{*}{0.749} & \multirow[t]{4}{*}{11} \\
\hline & & Mild limitation & 9 & 4 & & \\
\hline & & Severe & 2 & 4 & & \\
\hline & & limitation & & & & \\
\hline
\end{tabular}

*. Statistical significance stablished at $P \leq 0.05$ 